\title{
GLOBALIZACIÓN VERSUS UNIVERSALIZACIÓN CONSTITUCIONAL EN EL MEDITERRÁNEO. PROPUESTA METODOLÓGICA PARA UN ANÁLISIS DE LA DIVERSIDAD.
}

\author{
MANUELTEROL BECERRA \\ Catedrático de Derecho Constitucional \\ Universidad Pablo de Olavide Sevilla
}




\section{SUMARIO}

1. Aclaración preliminar. 2. Sobre la globalización. 3. Culturay Constitución. 4. De la universalización constitucional en el Mediterráneo. 4.1. El Mediterráneo aconstitucional. 4.1.1. Israel. 4.1.2. Libia. 4.2. Peculiaridades constitucionales de otros Estado islámicos mediterráneos. 4.3. Entre la esquizofrenia y el equilibrio. 5. REFLEXIÓN FINAL. 


\section{GLOBALIZACIÓN VERSUS UNIVERSALIZACIÓN CONSTITUCIONAL EN EL MEDITERRÁNEO. PROPUESTA METODOLÓGICA PARA UN ANÁLISIS DE LA DIVERSIDAD.}

POR

\section{MANUELTEROL BECERRA}

Catedrático de Derecho Constitucional Universidad Pablo de Olavide. Sevilla

\section{ACLARACIÓN PRELIMINAR}

A fin de evitar equívocos innecesarios no es ocioso advertir que en el presente trabajo la globalización desempeña una función instrumental y, por consiguiente, subordinada a la de su principal objeto de estudio, la indagación sobre la acogida dispensada a la idea de Constitución, más adelante se concretará cual, en los Estados ribereños del Mediterráneo. Naturalmente que eso no le resta ni un ápice de interés a la globalización. Máxime cuando ha influido hasta mover a redactar estas páginas la reflexión sobre la aptitud o ineptitud de ese fenómeno para explicar el de la proliferación de las Constituciones.

La conclusión alcanzada sobre su incapacidad al respecto tan sólo traslada el atractivo que encierran ambos fenómenos, aisladamente considerados, al que muestran observados desde la óptica de su confrontación, revelándose entonces la globalización un valioso contrapunto al que acu- 
dir para patentizar, por referencia a sus principales características, cuales son las del objeto de estudio individualizado. No se busque, por tanto, aquí ningún análisis detenido en torno a la globalización, ni más reflexiones sobre la misma de las que demande el apunte que, con la finalidad indicada, se ofrecerá a su respecto.

\section{SOBRE LA GLOBALIZACIÓN}

Quizá le asista la razón a Habermas cuando sostiene que algo tiene el término globalización de cajón de sastre1. Pero eso no es motivo para renunciar al intento de proceder con un mínimo de rigor en el uso de dicho concepto. Tanto más cuanto no se vislumbra demasiado difícil el empeño, considerando la abundante literatura existente sobre el particular. Tras cuya consulta se advierte enseguida que el término procede del mundo de la economía y que es allí en donde adquiere plenitud de significado. El cual, no se intentará individualizar aquí mediante una definición, pues se juzga más fructífero al respecto intentar enunciarlo en los términos descriptivos que, a tal objeto, emplean algunos de los más eminentes críticos de la globalización.

Tal es el caso de Noam Chomsky, quien informa de cómo hace cincuenta años quiso implantarse el orden económico mundial conocido como el sistema Bretton Woods, llamado a descansar sobre dos pilares de sustentación distintos aunque complementarios entre sí: la liberalización de la economía y la regulación del flujo de capitales. El propio Noam Chomsky revela la enorme importancia que este último asunto adquiría en el planteamiento de Bretton Woods. No era sólo que, desde una perspectiva teórica, la evasión de capitales, los flujos especulativos a corto plazo y las fluctuaciones de los tipos de cambio pudieran socavar la libertad de mercado. La regulación del flujo de capitales también se juzgaba una medida aconsejable por el peligro que representaba y puede decirse que representa para la democracia y el Estado de Bienestar la libre circulación de capitales ${ }^{2}$.

A este último propósito explica Noam ChomsKy como la posibilidad, por parte de un Estado, de controlar si el capital se mueve hacia dentro o

1 Cfr. Jürgen Habermas: "El valle de lágrimas de la globalización". Claves de razón práctica, núm. 109, p. 4/4.

2 Cfr. Noam Chomsky: "Los mercados y la sustancia de la sociedad". En la obra colectiva: Los límites de la globalización. Barcelona, Ariel, 2002, p. 20/32. 
fuera de sus fronteras le permite a su Gobierno llevar a cabo políticas monetarias y tributarias adecuadas para sustentar el empleo, los ingresos y los programas sociales, sin temor a que la evasión de capitales mine estas políticas. Eso sin contar con que el libre flujo de capitales propicia el nacimiento de lo que algunos economistas han llamado "un senado virtual». Un centro de poder no contemplado en la estructura orgánica del Estado, compuesto por instituciones financieras, en condiciones de imponer su propia política social mediante la amenaza de evasión de capitales, que, de producirse, en efecto, traeria consigo "tipos de interés más altos, ralentización económica, recortes presupuestarios en la sanidad y en la educación, etc., o tal vez una recesión o un colapso total”3.

No carece de importancia que, como indica también Chomsky, el sistema Bretton Woods fracasara en los años setenta, evidenciándose entonces, más próxima que lejana, la contingencia de conocer las economías $y$, por ende, las sociedades nacionales, esos riesgos recién descritos con las palabras del citado autor. Los cuales, conforme abandonan el terreno de lo pronosticable para mostrarse en el de lo verificable, generarían ese fenómeno al que se ha dado en llamar globalización.

Así al menos lo sostiene Chomsky, cuyo juicio definitivo sobre este asunto resulta ser tan sombrio como cabia esperar que lo fuera vistas sus consideraciones hasta aquí expuestas acerca del particular. No en balde, a renglón seguido de las mismas, volverá sobre el fracaso del sistema Bretton Woods para manifestar que desde ese momento se ha producido una ralentización del crecimiento económico y la productividad; el estancamiento de los ingresos y el deterioro de las condiciones laborales, así como de los servicios sociales y el colapso de las infraestructuras; el aumento de la encarcelación; el alza del desempleo; la elevación de los beneficios empresariales o mercantiles; y un incremento considerable del flujo de capital, en especial del que se produce a muy corto plazo, es decir, del especulativo 4 .

También Habermas se ha ocupado de señalar algunas características del nuevo orden económico mundial y ha reflexionado sobre el papel que podrían representar los Estados para mitigar las consecuencias negativas

3 Cfr. Ibidem, p. 33. En parecidos términos se expresa Habermas cuando sostiene que "el capital libre y sin trabas (...) puede amenazar con ejercer su opción de salida cada vez que un gobierno pone limitaciones onerosas a las condiciones para la inversión interna con la intención de salvaguardar sus niveles de protección social". Cfr. op. cit. p. 6.

4 Cfr. op. cit. pp. 34 y 35. 
del mismo. A pesar de su diagnóstico sobre la situación, cabe añadir, que las perspectivas de un intervencionismo estatal en tal sentido son poco halagüeñas. Téngase en cuenta que, para dicho autor, "como resultado de la globalización de los mercados el sistema económico internacional (...) se está metamorfoseando en una economía transaccional. Para ello son especialmente relevantes la aceleración de los flujos de capital (...). En la actualidad se trata más de Estados insertos en los mercados, que, de economías nacionales insertas dentro de las fronteras de los Estados» 5 .

Resulta del todo improcedente cuestionar aquí la información que acerca de la globalización ofrecen sus críticos. Tanto más cuanto la consulta realizada de los mismos ha sido, ciertamente, lo provechosa que cabía esperar. Quiere decirse con ello que si, en general, la crítica suele ser sugerente en cuanto a ideas, las formuladas por los autores citados responden a esas expectativas. Difícilmente podría decirse otra cosa, desde el momento en que, además de analizar las manifestaciones de la globalización en lo económico, atienden también a sus consecuencias en ámbitos distintos al de la economía. Recuérdense si no las palabras de Chomsky, más arriba citadas, relativas a este asunto, de las que se muestra complementaria la reflexión de Habermas en cuya virtud sostiene este último que el proceso en marcha de deterioro de las fronteras no afecta únicamente a la economía, sino también a las políticas internas globales, el mantenimiento de la paz y la violencia organizada, los nuevos medios y redes de comunicación o los florecientes movimientos migratorios y las formas culturales híbridas 6 .

Es más entre el conjunto de tendencias que aglutina el movimiento antiglobalizador, no falta la que propugna hacer frente a esas consecuencias generadas por la globalización en ámbitos ajenos al de la economía mediante acciones destinadas a producir efectos "de corte globalizante" en esas otras esferas. Tal es el caso de quienes aspiran a "globalizar" los derechos humanos $y$, en tal sentido, han redactado un manifiesto en el que demandan la "creación de un marco legal internacional que permita el cumplimiento efectivo de la Declaración Universal de los Derechos Humanos» 7 . Quede constancia de tal manifiesto y de su influencia en éstas páginas como elemento inspirador del tratamiento metodológico que en ellas se dispensa a la globalización $y$ a la proliferación de las

\footnotetext{
5 Cfr. op. cit. p. 4.

6 Cfr. op. cit. p.5.

7 Este puede consultarse e incluso suscribirse en: www.spglobal.org/spa-
} nish/home_spa.html. 
Constituciones, toda vez que ha movido a confrontar ambos fenómenos para aprehender sus respectivos significados.

\section{CULTURAY CONSTITUCIÓN}

Ahora bien, no obstante el posible uso de los datos mencionados, $y$ aun de otros parecidos que se pasarán por alto, como argumentos con que sustentar que, en efecto, algo tiene la expresión globalización de cajón de sastre, parece incuestionable que su significado es económico. Así instruye al respecto el Diccionario de la Real Academia Española, que, no en balde, define la globalización como «la tendencia de los mercados y de las empresas a extenderse, alcanzando una dimensión mundial que sobrepasa las fronteras nacionales».

Dicha circunstancia, que el vocablo adquiera plenitud de sentido en el mundo de lo económico, no es motivo suficiente para, en principio, prescindir de él en estas páginas, dedicadas, faltaba decirlo, a estudiar qué grado de implantación ha podido adquirir la idea de Constitución en los Estados ribereños del Mediterráneo. Pues, como no podía ser de otro modo, se juzga verosímil que esa idea haya podido traspasar los límites nacionales de donde procede para arraigar en lugares culturalmente extraños a los de sus orígenes. Si se considera inadecuado el empleo del término globalización para denominar a este último fenómeno no es por entender que así lo exija el recto uso del lenguaje, sino el de las categorías conceptuales. A cuyo propósito se estima que su valor semántico es sólo un componente más del que les corresponda conceptualmente.

Quiere decirse con ello que si el rasgo quizá más destacado de la globalización, en ausencia del cual no se llega a aprehender la noción de tal, es su acaecer autónomo o independiente de la voluntad estatal, e incluso a despecho de la misma, la Constitución escapa a la posibilidad de convertirse en su objeto, por tratarse de un fenómeno nacional. De modo que de ningún régimen constitucional puede esperarse que alcance dimensiones supranacionales de no mediar la colaboración al respecto de los Estados concernidos. Es más, aun cuando cualquier Constitución admita contemplársela desde la perspectiva propia de la cultura y ser considerada una de sus especies, ninguna participa de la nota característica que muestran los bienes de esa naturaleza - las piezas musicales o teatrales, los estilos arquitectónicos o los enunciados matemáticos-, en virtud de la cual circulan libremente más allá de las fronteras nacionales en donde nacieron y pueden llegar a convertirse en patrimonio de la humanidad. 
Una Constitución apenas llegará a integrar el patrimonio cultural del Estado que la adoptó. Otra cosa es su idea, que no sólo puede sino que ha trascendido los límites del Estado o Estados en donde surgió, como así lo evidencia la historia. No, desde luego, del modo en que lo hacen los bienes culturales mencionados, ni tampoco sus universales - la música, el teatro, la arquitectura o la matemática - , sino en forma de arquetipo.

Pero conviene obrar con orden y aclarar antes de proseguir que a lo cultural se le asigna aquí un significado muy amplio. Lo bastante para que apenas le sea ajeno cuanto concierne a la naturaleza, es decir a la vertiente de la realidad no humana y, por extensión, también, a las acciones humanas de carácter natural. Se inspira este planteamiento en las formulaciones de Mario Bunge sobre la cultura de las que informa Ferrater Mora en su Diccionario de Filosofía. En donde se dice que Bunge identifica a la cultura con un subsistema de la sociedad en la cual hay que tener en cuenta asimismo los subsistemas de la economía y de la política.

El que ninguna actividad social sea puramente económica, política o cultural vendría a expresar para Bunge que ninguna de esas especies, conformadoras del género más amplio sociedad, se mostraría autónomas de las restantes, pero no que resulte impracticable la tarea de diferenciarlas entre sí con el objeto de individualizar cada una. Así al menos se desprende de lo que sostiene sobre la viabilidad de aprehender lo específico de la relación que guarda el subsistema cultura con el sistema sociedad. A propósito de la cual, puntualiza que no obsta para que la cultura sea considerada susceptible de integrar otros subsistemas como el arte, la ideología, la tecnología, las humanidades, la ciencia o la matemática ${ }^{8}$. Enumeración esta de Bunge a la que se juzga oportuno sumar la religión y el subsistema jurídico que, en la actualidad, se entiende resultante de la Constitución del Estado.

He aquí el primer dato del otro asunto en el que conviene detenerse antes de proseguir. Pues, a fin de evitar equívocos innecesarios, se juzga oportuno aclarar que en estas páginas se identifica Constitución con documento escrito, concebido como norma suprema del ordenamiento jurídico compuesto por normas jerarquizadas entre si, de tal modo que las inferiores se fundamentan en las de rango superior, y así sucesivamente hasta llegar a la Constitución fundamento - inmediato o mediato- y límite de su respectiva validez. Quizá no sea ocioso añadir que si, dicho sea en otros términos, se entiende aquí por Constitución tanto como norma escrita

8 Cfr. José Ferrater Mora: Diccionario de Filosofia (nueva edición actualizada por la Cátedra Ferrater Mora, bajo la dirección de Josep-Maria Terricabras), Tomo I (A-D), voz cultura, Ariel Barcelona, 1994. 
capaz de condicionar la actividad normativa de los poderes del Estado, es porque, a un tiempo, se estima que la Constitución instaura esos poderes cuya tarea creadora del Derecho limita.

El segundo dato que interesa destacar acerca del concepto de Constitución al que se apela concierne a su contenido. Pues sólo se juzga merecedora de ser considerada tal la que, de conformidad con los postulados de los artículos 6 y 16 de la Declaración de los Derechos del Hombre y del Ciudadano de 1789, contempla mecanismos de garantía, para los derechos individuales que a la vez enuncia; define cuales son los órganos del Estado (precisando qué relaciones guardan entre sí y con los ciudadanos), con arreglo a lo exigido en el principio de separación de poderes; y concede carácter representativo a la asamblea encargada de adoptar las leyes, esto es, las normas que desarrollan de modo inmediato a la Constitución.

\section{DE LA UNIVERSALIZACIÓN CONSTITUCIONAL EN EL MEDITERRÁNEO}

Casi huelga decir que el modelo de Constitución descrito apenas pasaría de ser una mera construcción teórica de no haber mediado la voluntad de tantos Estados por adoptarlo. De ahí que prefiera utilizarse el término universalización a la hora de indagar respecto a su grado de implantación en los Estados ribereños del Mediterráneo, pues considerando que, según el Diccionario de la Real Academia, universalizar significa tanto como hacer universal algo, generalizarlo mucho, se ajusta mejor dicho término que el de globalización para indicar cual es el concreto objeto de estudio al que responden estas páginas.

Pues bien, el examen del universo elegido arroja un resultado ciertamente heterogéneo. Junto a los Estados que cuentan con Constituciones cuyas características coinciden con las atribuidas al modelo de tal que se ha propuesto, se sitúan los Estados que carecen de Constitución, o que si la tienen responden a una pauta constitucional distinta de la que siguen los mencionados inicialmente. Eso, sin contar la afinidad que guardan entre sí Chipre, Turquía y Albania, en tanto que Estados clasificables por su notoria inestabilidad política y constitucional. Entre los de esa primera categoría cabe citar, sin ánimo alguno de exhaustividad, los casos de España, Francia, Italia, Grecia y Malta, pues, aunque seguramente admiten residenciarse en este grupo las Constituciones de Serbia y Montenegro, Bosnia-Herzegovina, Croacia y Eslovenia, es preferible omitir dicha comprobación, por el motivo que enseguida se dirá. Israel y Libia se muestran desprovistos de Constitución. Mientras que pertenecen a la tercera clase de Estados casi todos, por no decir todos los demás del mundo musulmán. 
En cuanto a los regímenes constitucionales de los Estados clasificables en el primer grupo, se tiene muy presente la copiosa información que puede obtenerse a su respecto, mediante la consulta de los numerosos estudios que les ha dedicado la doctrina, como razón de peso para no proceder al análisis, necesariamente detenido, que, por eso mismo, demandan, y que rebasaría con mucho el objetivo perseguido en estas páginas realizar. Baste con la noticia que acerca de los mismos se ha ofrecido con el solo hecho de su catalogación, pues, aunque no se haya comprobado, al efectuarla, si las características atribuidas al modelo de Constitución por referencia al cual se ha construido dicha categoría taxonómica, son predicables de las Constituciones vigentes en los Estados mencionados, puede prescindirse, pese a todo, de dicha verificación $y$ afirmar que tales coincidencias se producen, desde el momento en que el concepto prototípico que se ha ofrecido de Constitución se ha obtenido asignándole las características que se entienden comunes a las Constituciones de esos Estados.

Tampoco se analizarán las Constituciones de los Estados de reciente creación mencionados, por estimarse prematuro cualquier juicio a su respecto $^{9}$, ni, por esa misma razón, los regímenes inestables de los Estados también citados más arriba ${ }^{10}$. Sí se examinará, en cambio, siquiera sea de manera sucinta, la relación que guardan con el modelo de Constitución aquí adoptado las situaciones o realidades jurídico-políticas, aparentemente más asentadas, de Israel y Libia, así como de los Estados que mediante sus respectivas constituciones adoptan el Islam como religión oficial, además del caso libanés.

\subsection{El Mediterráneo aconstitucional.}

\subsubsection{Israel.}

Uno de los Estados que, según se adelantaba, carece de Constitución es Israel. Su propio Gobierno inf̣orma de cómo poco después de obtener la independencia y a fin de evitar un vacío normativo, se resolvió adoptar

9 A este propósito es significativo que no esté disponible en la página web de International Constitutional Law (I.C.L.), la edición completa de la Constitución vigente de Serbia y Montenegro. De modo que sólo pueden consultarse alli sendas traducciones no oficiales, francesa e inglesa, de la misma. Cfr. www.oefre.unibe.ch/law/icl.

10 Como sucede en el caso de Serbia y Montenegro, tampoco en los de Chipre, Turquía ni Albania, ofrece la página web del.C.L ediciones completas de sus textos constitucionales. Cfr. Ibidem. 
la Ley sobre Ordenanzas y Administración, en virtud de la cual asumia el nuevo Estado el ordenamiento vigente en su territorio inmediatamente antes de ese momento fundacional, siempre y cuando dicho ordenamiento no fuera contradictorio con los principios enunciados en la Declaración de Independencia del Estado de Israel, proclamada el 14 de mayo de 1948, ni con las leyes que aprobara el Parlamento israelí, la Kneset. De este modo, el nuevo Estado contó inicialmente con un ordenamiento compuesto por ciertas normas vestigio de la presencia turca en Palestina hasta 1917; las que rigieron alli durante el mandato británico, desde 1918 hasta 1948, pertenecientes en su mayor parte al Derecho consuetudinario inglés; elementos de la ley religiosa judía; y alguna que otra norma procedente de sistemas jurídicos distintos de los mencionados ${ }^{11}$.

Con esto solventaba el naciente Estado israelí su necesidad perentoria de un ordenamiento con el que iniciar su andadura. Las instituciones que por fuerza habría de crear la Asamblea Constituyente, convocada en la Declaración de Independencia12, se encargarían de hacer el resto. Había que dar tiempo al tiempo para que aquellas enriqueciesen con sus aportaciones ese ordenamiento inicial mínimo. El cual, en efecto, ha conocido, desde 1948, un incremento paulatino con la sucesiva incorporación al mismo de nuevas normas. De entre las que interesa destacar un selecto grupo usualmente conocido como el de las Leyes Básicas, de ordinario identificadas, a su vez, por el nombre de la institución o el asunto que respectivamente regulan, esto es, la Kneset (1958), el Territorio del Estado (1960), el Presidente (1964), el Gobierno (1968), la Economía del Estado (1975), el Ejército (1976), Jerusalén (1980), el Sistema Judicial (1984), el Interventor del Estado (1988), la Dignidad y la Libertad Humanas (1992), y la Libertad de ocupación (1992) ${ }^{13}$.

Visto el protagonismo del Common Law británico en la tarea conducente a la construcción del sistema jurídico israelí, es comprensible que haya influido también Inglaterra para que, antes o después, se haya con-

11 Cfr. www.israel.org/mfa/go.asp?MFAH01s10.

12 A este respecto instaba dicha Declaración a que esa Asamblea Constituyente fuera elegida no más tarde del 1 de octubre de 1948.

13 Cfr. Ibidem. En la página web de I.C.L. se ofrece información respecto a la actualización de tales Leyes Básicas, especificándose que son las atinentes al Gobierno (1992), el Presidente del Estado (1964), la Kneset (1987), el Sistema Judicial (1984), el Territorio del Estado (1960), Acuerdo sobre Jericó y la franja de Gaza (1995), la Economía del Estado (1983), el Ejército (1976), Jerusalen (1980), el Interventor del Estado (?), la Libertad de Ocupación (1992, 1994), y la Dignidad y la Libertad Humanas (1994). Cfr. www.oefre.unibe.ch/law/icl/is_indx. $h$ tml. 
templado el conjunto de Leyes Básicas recién citadas como la Constitución de Israel. Quiere decirse con ello que, aun cuando se aprobaran sin mediar el propósito de comunicarles ese carácter, como se verá, después de adoptárselas parece haber surgido la idea de asignárselo, acudiendo a los fundamentos que, en tal sentido, aporta la experiencia británica. Conviene subrayarlo, pues sería en vano negar la ausencia de argumentos, inspirados en formulaciones inglesas, con que sustentar la dimensión constitucional de las Leyes Básicas, ni la de quienes los esgrimen dentro y fuera de Israel14. Sin perjuicio de lo cual cuesta concluir afirmando que con la aprobación del conjunto normativo expresado se haya resuelto allí satisfactoriamente la cuestión constitucional. Máxime cuando cabe deducir lo contrario de su corta pero intensa historia, cuya consulta al respecto se juzga pertinente considerando la íntima relación que evidencian guardar dicha cuestión y la atinente a la construcción del Estado.

Para calibrar la intensidad del vínculo que anuda a la cuestión constitucional en Israel con su proceso de construcción nacional conviene tener en cuenta que el documento directriz de la transición política israelí, esto es, su Declaración de Independencia, encierra un ambicioso proyecto de construcción nacional, en cuya virtud, tras una ineludible situación de interinidad, obtendría el Estado de Israel la estabilidad que habría de comunicarle la aprobación de una Constitución.

En ningún momento, pues, pretendió hacerse de la Declaración de Independencia la Constitución de Israel. Antes bien, se contaba con la adopción de esta última para levantar el edificio estatal apenas esbozado en aquel documento, de forma que dicho edificio hubiera de reposar en la futura Constitución como uno de sus pilares básicos. No en balde, invitaba la Declaración de Independencia a la aprobación de una Constitución llamada a desempeñar como principal tarea la de fundar el Estado de Israel. Por cierto que en los siguientes términos literales:

"Nosotros declaramos que, con efectividad desde la terminación del Mandato, esta noche víspera del sábado, sexto de lyar de 5708 (15 de mayo de 1948), hasta el establecimiento de las autoridades electas, regulares del

14 Entre los del primer grupo cabe citar a Gabriel BenTasgal, para quien aunque Israel no posee una Constitución escrita tiene una Constitución material configurada por leyes comunes, las Leyes Básicas y diferentes precedentes judiciales. Cfr. "La base legal en Israel: Un país sin Constitución". En www. wzo.org.il/es/recursos/view.asp?id=1086. Desde fuera baste con señalar que en la página web de I.C.L. (www.oefre.ch/law/icl/is indx.html), las Leyes Básicas de Israel son consideradas sus leyes constitucionales, del mismo modo que la situación de este Estado asimilable a la de Canadá y Nueva Zelanda. 
Estado, de conformidad con la Constitución que será adoptada por la Asamblea Constituyente, elegida no más tarde del primero de octubre de 1948, el Consejo del Pueblo actuará como Consejo Interino del Estado, y su órgano ejecutivo, la Administración del Pueblo, será el Gobierno Provisional del Estado judío, que se habrá de llamar «lsrael»"15.

Todavía interesa llamar la atención sobre la enorme complejidad que reviste el proceso de construcción nacional israelí. De sobra la tiene presente Carmen López Alonso cuando califica el fenómeno como un caso paradigmático o singular entre los de su especie, tras sostener que no existe un modelo para explicarlo unilateralmente. No sólo, añade la citada autora, porque en él hayan influido hechos externos como la descolonización o el holocausto, insólitos, cuando no ausentes, en otros procesos de construcción nacional, sino también porque dicho proceso se prolonga hasta la actualidad16. Como, por cierto, así entiende que sucede el historiador israelí Zeev Sternhell, quien, no en balde, afirma sobre el particular que Israel sería todavía un país no terminado, "una nación laboratorio»17.

Pues bien, dada la intensidad de la relación que guarda la cuestión constitucional en Israel con su proceso de construcción nacional, no sorprende encontrar comunicada aquella por la principal característica que impregna el fenómeno en el cual cabe entender que se inscribe. Nada tiene de particular que, en definitiva, el proceso tendente a dotar de una Constitución al Estado israelí también se muestre rodeado de complejidad.

Según informa al respecto Gabriel Ben Tasgal, antes de la independencia se había formado una Secretaría conocida con el nombre de su Presidente, Zeraj Varhaftit, encargada de redactar una Constitución para el Estado por nacer. A causa de la guerra, la elección de la Asamblea Constituyente prevista en la Declaración de Independencia, como muy tarde, para octubre de 1948, no se efectuó hasta febrero de 1949. Inmediatamente acordó dicha Asamblea dictar la Ley de Transición 1949 (JokHaMaaver 1949), en cuya virtud el Parlamento sería denominado en adelante Kneset y la Asamblea Constituyente considerada la primera Kneset. También de modo inmediato reanudó el órgano la discusión inicia-

15 Cfr. Declaración de Independencia del Estado de Israel. En www.wzo.org.il/es/recursos/view.asp?id=1022. El subrayado es nuestro.

16 Cfr. "Israel ¿nación laboratorio?". En www.ucm.es/info/historia/Secund/profesorado/Articulos/lsrael//srael.htm.

17 Expresión ésta que, como puede comprobarse, toma prestada Carmen López Alonso para rubricar su artículo, según informa puntualmente al respecto cuando expone las reflexiones de Zeev Sternhell sobre este particular. 
da en la Secretaría Zeraj Varhaftit sobre la Constitución entre posiciones encontradas. La de quienes pedian redactar una Constitución, por entender que a ello comprometía la Declaración de Independencia, y la de quienes se oponían a su aprobación, los partidos religiosos, por estimar que la única ley suprema era la Halajá (Ley religiosa) y que la Constitución no podía obviar un tema tan espinoso para Israel como el de la relación religión-Estado, de una parte, y el partido gobernante "Mapai», liderado por el Primer Ministro David Ben-Gurión, de otra, por las razones que luego se verán 18 .

Así las cosas, el 13 de junio de 1950 el Parlamento acordó, mediando el voto de 50 Diputados a favor, frente a 39 en contra, aceptar la propuesta del Diputado del Partido Progresista Izahar Harari, según la cual:

"La primera Kneset ordena a la Secretaría de Constitución, Ley y Jurisprudencia elaborar una propuesta de Constitución para el Estado. La Constitución estará conformada por grandes artículos, cada uno de los cuales será una ley básica. Cada artículo será expuesto ante la Kneset, y cuando la Secretaria culmine su trabajo, todos los artículos serán reunidos en una Constitución para el Estadon.

Tal es la información que ofrece al respecto Gabriel Ben Tasgal, para quien, en definitiva, Harari propuso que una Secretaría de la Kneset asumiera la función de la Asamblea Coństituyente $y$, paso a paso, preparara una Constitución a muy largo plazo para Israel19.

Desbordaría con mucho el objetivo que persiguen estas páginas indagar sobre los logros que, en todos estos años, haya podido alcanzar el Parlamento israelí en el ejercicio de su tarea constituyente. Más interesa concentrar la atención en la citada solución de compromiso, mediante la cual, obsérvese bien, no renunciaba la Asamblea Constituyente, transformada en primera Kneset, a que Israel contara con una Constitución, por más que pospusiera sine die el momento de su adopción. Considérese si no proporciona dicha circunstancia un argumento de peso con ayuda del cual sustentar, como aqui se hace, que Israel carece de Constitución. Tanto más cuanto no faltan allí voces autorizadas que la demanden en la actualidad.

Tal es el caso de Abrahám Burg, Presidente de la Kneset, al menos cuando se celebró el quincuagésimo primer aniversario de su creación, esto es, el 1 de febrero de 2000, quien con esta ocasión publicó un artículo significativamente titulado: «El cumpleaños de la Kneset: La hora de la

18 Cfr. Gabriel Ben Tasgal: "La base legal en Israel: Un pais sin Constitución". Cit.

19 Cfr. Ibidem. 
Constitución". En él decía, entre otras cosas, que los israelíes se ocultaban tras la túnica del statu quo para engañarse a sí mismos. En su opinión, los defensores del statu quo adoptaban un punto de partida erróneo. Según decía, "Ben-Gurión y sus seguidores creyeron que en veinte años más la ortodoxia desaparecería, mientras que los ortodoxos estaban convencidos que el capricho de los jóvenes sionistas desaparecería del mundo y la gloria de la tradición volvería a reinar. Entonces, entre tanto, ambas partes acordaron congelar la realidad. Pasaron los días, siguieron los años $y$ resultó que ninguna de las dos desapareció» 20 .

Pero, a grandes males los grandes remedios que para Burg habría de traer consigo la Constitución: «si somos amantes de la vida debemos dar basamento, y rápido, a un nuevo principio fundamental que reemplace al status quo que artificialmente exacerbó nuestro espíritu. Una Constitución es un nuevo principio fundamental " 21 .

Ahora bien, los datos hasta aquí referidos no son los únicos en virtud de los que adquiere interés la complejidad de la cuestión constitucional israelí. Por atractivos que puedan considerarse éstos, incluida la conclusión que, subsiguientemente a su examen, cabe sostener respecto a la ausencia en Israel de una Constitución racional normativa, no lo es menos que su idea ha recibido alli una excelente acogida. Así autoriza a sostenerlo cierto hecho cuyo relato se ha dejado deliberadamente para el final.

Según la información que al respecto proporciona Gabriel Ben Tasgal, en 1953 un diario israelí publicó que Israel cedería doscientos mil soldados a Estados Unidos si éste país decidía combatir a la Unión Soviética. El Gobierno israelí negó el contenido de la información, pero no logró evitar que estallara la polémica, en el curso de la cual el periódico del Partido Comunista de Israel, Kol Haam (La Voz del Pueblo), acusó al Gobierno de jugar a la guerra y de regalar la sangre de los jóvenes 22.

El Ministerio del Interior decidió cerrar el periódico invocando una ley que le permitía hacerlo cuando la prensa amenazase la paz pública, y el diario recurrió tal decisión a la Corte Suprema de Justicia. La cual manifestó no estar en condiciones de emitir un juicio definitivo sobre si La Voz del Pueblo hizo peligrar o no la paz pública debido a que la ley aplicable al caso admitía varias interpretaciones y que, mediando dicha circunstancia,

20 Cfr. www.wzo.org.il/recursos/view.asp?id $=596$.

21 Cfr. Ibidem.

22 Cfr. Gabriel Ben Tasgal: "La Declaración de Independencia de Israel y su importancia". En www.barujataadonai.com/sionismo/ 38LaDeclaracion.htm. 
había de resolverse, como hizo, según el espíritu de la Declaración de Independencia, en la cual se promete libertad de expresión 23 .

He aquí el ascendiente de la idea de Constitución en un Estado sin Constitución que acepta provisionalmente todos los modelos constitucionales para, de este modo, no adoptar a la postre ninguno. Tal es la fuerza de un elemento perteneciente a un sistema cultural más reciente en otro distinto atento a una tradición más antigua.

\subsubsection{Libia.}

El caso de Libia es distinto dado que alli se ha renunciado a la idea de adoptar una Constitución. No cuando en 1969 se produjo el derrocamiento del Rey Idris. Entonces la Jefatura del Consejo Revolucionario aprobó un documento con tintes constitucionales, una Constitución de urgencia, por decirlo con las mismas palabras que usa Pedro Cruz Villalón para calificar a la Declaración de los Derechos del Hombre y del Ciudadano de 1789 , buscando con ello resaltar que con su aprobación quería expresar la Asamblea Nacional francesa voluntad de ruptura con el antiguo régimen, así como de compromiso con el pueblo francés e internamente, consigo misma, en orden a recorrer el camino conducente a la aprobación de una Constitución. A la espera de la cual, pues llevaría algún tiempo redactarla, se ofrecía el avance de sus bases, al objeto de imprimirles, no obstante, el carácter provisorio de dicha Declaración, eficacia inmediata 24.

El documento libio indicado es el que en forma de texto articulado publicó la Jefatura del Consejo Revolucionario el 11 de diciembre de 1969, haciendo constar en él la firme determinación de eliminar todo vestigio de la monarquía recién derrocada $25, y$, consecuentemente con ello, la de dotar al Estado de una estructura orgánica nueva, aparentemente inspirada en el principio de separación de poderes ${ }^{26}$. También eran proclamados allí una

23 Ibidem.

24 Cfr. Pedro Cruz Villalón, El Estado de sitio y la Constitución, Madrid, Centro de Estudios Constitucionales, 1980,p. 224.

25 No en balde, su art. 33 anulaba la Constitución de 7 de octubre de 1955, hasta entonces vigente.

26 En este sentido, sus artículos 18 y 19, trataban, sucesivamente, de la Jefatura del Consejo Revolucionario (al que se le encomendaba el ejercicio de la potestad legislativa, sin que constara su carácter electivo), así como del Presidente y del Consejo de Ministros (destinados a desempeñar la función ejecutiva). Mientras que sus artículos 27 y 28 se ocupaban de la judicatura. 
serie de derechos individuales, cuya garantía se confiaba a la ley, igual para todos, y a la acción judicial. Tal era el contenido del documento concebido como medida provisional a la espera de la Constitución 27.

Sin embargo, transcurridos algo más de siete años desde su formulación se decidió abandonar el mencionado proyecto. Así consiente afirmarlo el tenor del documento publicado el 2 de marzo de 1977, por el que se proclamaba el Establecimiento o Instalación de la Autoridad del Pueblo y se adoptaba para Libia el nombre oficial de Jamahiriya árabe del pueblo socialista». Pues, no en balde, su art. 2 dispone que el Coran es la Constitución del Jamahiriya árabe del pueblo socialista.

Con ello vendría a manifestarse oficialmente en Libia un pensamiento musulmán sunni bastante extendido, según cabe deducir de lo que informa al respecto Yadh Ben Achour, cuando afirma que hoy es corriente oír en un país islámico la expresión "el Coran es nuestra Constitución»; o leer en sus Constituciones escritas: «el Islam es la religión del Estado o la fuente principal de legislación»; o bien escuchar la expresión más genérica: «el Islam es nuestra Constitución» 28.

De sobra es conocida en el mundo judeo-cristiano la idea de una alianza entre Dios y los hombres. Tanto que casi huelga mencionarla, o que su relato bíblico ha llevado a considerar el Viejo $y$ el Nuevo Testamento plasmaciones de esa clase de pacto. En cambio, es seguramente menos conocido el predicamento de esa idea en la religión musulmana. Pues, en efecto, tampoco faltan entre sus fieles quienes ven el Coran como una alianza de aquella naturaleza 29 . Recuérdese además que es inherente a la idea de Constitución la de acuerdo o contrato fundacional de la sociedad

27 En esto, su art. 37 era concluyente: "La presente proclamación constitucional tendrá efectos entre tanto no se emita una Constitución definitiva".

28 Cfr. Yadh Ben Achour: LA théorie constitutionnlle dans la tradition sunnite. En www.univ-tlse.fr/publications/Colloques/Constitution/Achour.html.

29 En este sentido, nos atrevemos a esgrimir como argumento que el Coran, sura 2, verso 103, dice: "Y aferraos fuertemente todos juntos con la cuerda de Al-lah y no os dividáis; y recordad el favor de Al-lah que El os concedió cuando erais enemigos y El unió vuestros corazones en el amor, para que con su gracia os hicierais como hermanos; estabais al borde de un abismo de fuego y El os salvó. Así os explica Al-lah sus mandamientos, para que seáis guiados".

Conviene advertir que usamos un Coran bilingüe, en árabe y en español, publicado en Córdoba (España) por Islam International Publications, Ltd., en 1988, cuya traducción asumen Antonio Carrillo Robles y Mansur Ata llahi. A ellos ha de imputársele la nota a pie de página del vérsiculo citado, destinada a explicar que han decidido emplear el 
política, extremo este sin duda difundido en los países donde se practica el Islam. Pues bien, pónganse en contacto ambas ideas y obsérvese con cuanta facilidad cabe extraer, entre otras varias conclusiones posibles, la de contemplar el Coran como pacto o acto fundacional de la sociedad islámica, la Ummah.

Pero interesa decirlo con las palabras de Yadh Ben Achour, a fin de cuentas inspiradoras de las reflexiones que anteceden. No en balde, es él quien sostiene que "la idea de alianza entre un Dios y un Pueblo existe en el Coran. La diferencia con la Biblia es que en el Coran la sangre (Israel) y la tierra (prometida) han desaparecido. La sangre es la de los humanos y la tierra el planeta entero. El nudo que ata es pues inmaterial, es la fe pura. La Ummah es una comunidad política de fe» 30 .

En definitiva, pues, cuando el documento libio de 2 de marzo de 1977 dice que el "Sagrado Coran es la Constitución del Jamahiriya árabe del pueblo socialistan, cabe estimar que quiere conferirle al Coran la conside-

vocablo "cuerda" para traducir la voz coránica "habl", ofreciendo con tal aclaración tanta información complementaria que optamos por reproducir la nota en su integridad:

"Habl significa un cable o una cuerda con la que se sujeta o ata una cosa; un lazo; una alianza o pacto; una obligación por la que uno se hace responsable de la seguridad de una persona o cosa; alianza o protección (Lane). El Santo Profeta dijo: 'el libro de Dios es la cuerda de Al-lah que ha sido extendida de los cielos a la tierra' (Llarir, iv.30)".

Hasta aqui la nota, ignoramos que quiere decir eso de "(Llarir, iv.30)", pero hemos encontrado las traducciones de sendos hadices que, con otras palabras, vienen a decir lo mismo. Del primero ignoramos el dato trascendental de su procedencia, aunque entendemos que se trata de un olvido involuntario de su traductor, por lo que juzgamos oportuno citarlo: "¿Es que no os he dejado dos cosas de gran peso? Una de ellas es el libro de Al-lah, que es la cuerda de Al-lah. Quien la sigue está en la guía recta y quien la deja está extraviado" (Cfr.www.webislam.Com/BEI /jardines/trato.htm).

En cuanto al segundo no albergamos dudas sobre su procedencia, de ella informa puntualmente la fuente consultada, en donde pude leerse que "Ahamad y at-Tabari comunicaron el Hadiz de Çaid ibn az Zâbit según el cual el nabi (s.a.s.) dijo:

Dejo entre vosotros a dos sucesores míos: el libro de Al-lah que es una cuerda tendida entre el cielo y la tierra y mi Clan, la gente de mi Casa. Ninguno se separará del otro hasta que beban del estanque.

Es decir - continua la fuente consultada-, no lo harán jamás. El estanque del Profeta (s.a.s.) está más allá de la muerte"(Cfr. www.zawiya.org/Zawiya-Bolet\%C3\%ADnzhtm).

Pues bien, considerando cuanto ha venido diciéndose, no parece descabellado sostener que en la exhortación coránica a los musulmanes para que se aferren a la cuerda, esta última resulta ser el Corán mismo, susceptible, a su vez, de entenderse, si "habl" admite la significación que le conceden los traductores citados, como la alianza entre Dios y quienes profesan el islam.

30 Cfr. "La théorie constitutionnelle dans la tradition sunnite". Cit. 
ración, entre otras cosas, de alianza fundacional de la sociedad política libia. Difícilmente podrían pretender sus redactores ir más allá, ni entenderse tal afirmación de otra forma, pues, abstracción hecha del problema que entraña el intento de dar respuesta a la cuestión del poder constituyente desde el Coran, es obvio que sus contenidos se alejan por completo no ya del asignado al modelo de Constitución que preside estas páginas, sino de cualquier idea de Constitución. Téngase en cuenta que, según informa al respecto, Yadh Ben Achour, el texto coránico contiene normas obligatorias en su mayor parte de carácter moral, junto a otras de naturaleza jurídica que conciernen al derecho penal, el matrimonio, el divorcio y la filiación, así como el derecho sucesorio. Poco, pues, tiene de materia constitucional el Coran, concluye afirmando el citado autor ${ }^{31 .}$

Eso no quiere decir que en Libia se ignore el significado que aquí viene concediéndosele a la Constitución. El tenor del documento adoptado en 1969 es elocuente al respecto, por eso se le calificaba más arriba como una Constitución de urgencia. Tampoco la afirmación, efectuada en el documento de 1977, relativa a que el Coran es la Constitución libia parece tener otro sentido que el puramente político de renuncia a una Constitución en favor de un documento que no lo es, con lo que esa opción encierra de receptividad a la idea de Constitución como arquetipo, cuando menos.

\subsection{Peculiaridades constitucionales de otros Estado islámicos mediterráneos.}

En cuanto a los demás Estados musulmanes ribereños del Mediterráneo, ninguna duda cabe de su receptividad a la idea de Constitución. Asi lo evidencia el que todos ellos, Marruecos, Argelia,Túnez, Egipto, Líbano y Siria cuenten con sendas Constituciones escritas. Cuestión distinta es la peculiaridad que adquieren la mayoria al declarar, de un modo u otro, la confesionalidad islámica del Estado correspondiente. De ahí el calificativo de musulmanes que aquí se les aplica con la única excepción del Líbano.

Así, la constitución marroquí proclama en su art. 6 que "el Islam es la religión del Estado, el cual, garantiza la libertad de cultos»; y dispone en su art. 19.1 que «el Rey (...) asegura la observancia del Islam y la religión». Similar es el tratamiento de la cuestión religiosa en la Constitución argelina, pues prescribe su art. 2 que «el Islam es la religión del Estado»; y pro-

31 Ibidem. 
híbe en su art. 9 "prácticas contrarias a la moral islámica». Por su parte, la Constitución tunecina destina su art. 1 a proclamar que "Túnez es un Estado libre, independiente y soberano, cuya religión es el Islam", declaración esta que completan sus artículos 38 y 40 exigiendo que la religión del Presidente de la República sea el Islam. La Constitución egipcia declara en su art. 2 que el «Islam es la religión del Estado y el árabe su lengua oficial. Los principios de la Ley islámica constituyen la fuente principal de legislación».Y, en parecidos términos, se manifiesta la Constitución siria cuyo art. 3.1 establece que la "religión del Presidente de la República tiene que ser el Islam»; ocupándose el art. 3.2 de añadir que «la jurisprudencia islámica es la fuente principal de legislación” 32 .

Poca importancia se le concede aquí a las diferencias apreciables entre los enunciados constitucionales transcritos porque digan que el Islam es la religión del Estado, exijan al Jefe del Estado que la profese, o asuman el Islam como la principal fuente normativa. Obsérvese que, en cualquier caso, cabe estimarlos fórmulas orientadas a incorporar el Derecho islámico derivado de interpretar el Coran y la Sunna en los respectivos ordenamientos nacionales ${ }^{33}$. Con lo que eso implica de obstáculo insalvable en orden a considerar que en tales Estados sus Constituciones operen como normas supremas de sus respectivos ordenamientos. No se descarta en absoluto que cada una de aquellas Constituciones pretenda erigirse en fundamento y límite de la actividad legislativa que despliegue el Estado correspondiente, pero es obvio que ninguna Constitución puede serlo de las normas inspiradas en el Coran y la Sunna. Eso, si no es que uno y otra terminan por condicionar la validez de cuantas normas se adopten en el Estado considerado.

\subsection{Entre la esquizofrenia y el equilibrio.}

Tal es la influencia que en Marruecos, Argelia, Túnez, Egipto y Siria habría ejercido la idea de Constitución adoptada en estas páginas.

32 Varias son las páginas web en donde pueden consultarse tales Constituciones. No es raro que las embajadas abiertas por tales países en Estados iberoamericanos ofrezcan, incluso, traducciones españolas de sus respectivas Constituciones. En todo caso, sus versiones en inglés, están disponibles en www.oefre. unibe.ch/law/icl.

33 Así sucede, incluso cuando se le exige al jefe del Estado profesar la religión islámica, por lo que eso significa en punto a concebírselo como "Imán de los creyentes" o director espiritual de los musulmanes sobre los que ejerce su potestad temporal, y de confianza en que sus acciones se ajustarán a lo establecido en la Ley islámica. 
Desbordaría con mucho el objetivo al que atienden estudiar con el detenimiento debido cómo se las arreglan en tales Estados para solucionar las inevitables fricciones que, de seguro, se producen en sus ordenamientos entre Constitución y Derecho islámico. Sea como fuere, por si fueran pocas las contradicciones que, en los tiempos presentes, desgarran al mundo árabe-musulmán, ha de sumarse esta última a la lista que, encabezada por el debate entre «la adhesión a su herencia intelectual y cultural y la modernidad", ofrece al respecto Yadh Ben Achour. Quien, a la vista de tales contradicciones no duda en hablar de la esquizofrenia histórica en la que viven los países árabes 34 .

Pues bien, a este último propósito, se juzga aquí que no hace sino potenciar dicha psicopatía o, más exactamente, la manifestación de la misma en cuya virtud adquiere interés para éstas páginas, el predicamento que, en los países árabes, $y$, por tanto, también, en los que vienen considerándose, alcanza un documento por entero privativo de la cultura árabe, conocido como la "sahifa" o "Constitución de Medina". La cual data de los primeros años de la Hégira, y admite considerarse como la plasmación escrita de un pacto o acuerdo tendente a crear una Comunidad política compuesta por musulmanes emigrados de la Meca, musulmanes de Medina, $y$ no musulmanes, en concreto familias judias a las que se les reconocía libertad de culto; entre cuyos objetivos resaltaba el de prestarse ayuda mutua en caso de guerra ${ }^{35}$. Documento que, modernamente, reivindican los intelectuales árabes como la primera Constitución escrita del mundo ${ }^{36}$.

La enorme complejidad del fenómeno descrito confiere tanto mayor interés a la Constitución libanesa. No porque acierte a ofrecer una solución satisfactoria para resolver la contradicción resultante de integrar en un mismo ordenamiento dos normas, la Constitución y el Coran, con idéntica vocación de presidirlo, sino porque prescinde o, mejor, tiende a prescindir de uno de esos dos documentos normativos.

$34 \mathrm{Cfr}$. "Les constitutions des pays arabes. Conclusions generales". En www.fdsp.usj.edu.lb/cedroma/.

35 Una versión española de esta "sahifa", debida a la traducción de Abdullah Tous y Na_at Labrador, puede encontrarse en www.musulmanesandaluces.org/publicaciones/sir a-ll/sira24.htm.

36 Cfr. el breve comentario que le dedican los autores de la traducción española citada en la nota anterior, así como las repetidas alusiones a su respecto de Yadh Ben Achour, en "la théorie constitutionnelle dans la tradition sunnite". Cit. Aunque también en España parece haber despertado interés el documento, a juzgar por la atención que le presta Javier Jordán Enamorado en su trabajo "Islam y democracia". En www.ugr.es/ceas. 
Pues, en efecto, aunque socio fundador de la Liga de Estados Árabes ${ }^{37}$ y de la Conferencia Islámica ${ }^{38}$, el Líbano es el único Estado mediterráneo de tales características que cuenta con una Constitución escrita, en la cual no sólo falta una declaración de confesionalidad islámica del Estado, como las que incluyen, según ha podido verse, las Constituciones de Marruecos, Argelia, Túnez, Egipto y Siria, sino que acoge otra mediante la cual la Constitución, expresa, con rotundidad, el propósito de abandonar el modelo de Estado confesional. $Y$ habida cuenta del tiempo transcurrido desde su formulación ha de presumirse que el Líbano se encuentra inmerso en un proceso orientado a su transformación en un Estado laico. No en balde, manifiesta al respecto el preámbulo añadido a su Constitución, el 21 de septiembre de 1990, que "la supresión del confesionalismo político constituye un objetivo nacional esencial por cuya realización se impone trabajar acorde a un plan por etapas».

Tan ambicioso propósito exigía un tratamiento de la libertad religiosa que estuviese a la altura de las circunstancias $y$, ciertamente, puede decirse que no desmerece del mismo el que le concede la Constitución libanesa a este asunto en su art. 9:

"La libertad de conciencia es absoluta. El Estado al cumplir con las obligaciones de adoración a Dios, respeta todas las religiones y ritos $y$ garantiza el libre ejercicio de los cultos religiosos bajo su protección, siempre que ello no perturbe el orden público. El Estado garantiza, asimismo, a los ciudadanos de cualquier culto el respeto del régimen de los estados personales y los intereses religiosos» 39 .

\section{REFLEXIÓN FINAL}

Se aleja demasiado del objetivo al que responden estas páginas indagar respecto a la posible existencia en Marruecos, Argelia, Túnez, Egipto y Siria, de un debate acerca del mayor o menor grado de armonía con su cultura compartida de la "Constitución de Medina" y de la Constitución del Líbano. Sea como fuere no debe descartarse que haya en

37 La lista de su composición puede obtenerse en www.árabe. galeon.com/pmundoarabe.htm.

38 De sus paises miembros informa www.árabe.galeon.com/ ppaisesoci.htm.

39 Una versión española de la Constitución libanesa vigente puede consultarse en www.ellibano.com.ar/politica/preparacion.htm. 
esos lugares quienes juzguen más rigurosamente representativa de ese sustrato cultural común a una que a otra. Como tampoco es improbable que entre los inclinados a suscribir una opción concreta de la alternativa propuesta los hubiese resueltos a completar su juicio teórico sobre el particular con una reflexión, no menos especulativa y acaso apologética en torno a los méritos que reúne la fórmula objeto de sus preferencias para erigirse en el modelo a imitar en tales Estados.

Sorprendería que en una discusión como ésa no saliera a relucir, antes o después, la cuestión de qué religión habría de profesar la persona llamada a representar la jefatura del Estado, pues así como parecía ocuparse de este asunto la "Constitución de Medina", no puede decirse que lo haga la Constitución del Líbano. Ante lo cual nada tendría de particular que los hipotéticos simpatizantes de la "Constitución de Medina" se mostraran inflexibles en punto a exigir que el Jefe del Estado sea musulmán, considerando el liderazgo, acreditado en dicho documento, que ejerció el propio Mohamed sobre aquella comunidad medinense, fundada con arreglo a lo estipulado en la "sahifa".

La sola duda de si los defensores del modelo constitucional libanés compartirían o no dicho planteamiento encierra en sí misma una razón para el desencuentro entre aquellos y los partidarios de la "Constitución de Medina». El único, cabe añadir, de carácter invencible. Pues sería exagerado sostener que en lo demás muestren los textos considerados incompatibilidades insuperables. Ni siquiera la diferencia seguramente más acusada de entre cuantas puedan separarlos, definida por la distancia temporal y conceptual que media entre un documento del siglo VII, por eso mismo aconstitucional, aun cuando pretenda hacérsele pasar hoy por una auténtica Constitución, y un texto contemporáneo digno de ser estimado tal, tampoco esa disparidad cronológica y conceptual es insalvable si, como aquí viene haciéndose, se considera a la Constitución libanesa como el documento heredero del espíritu que impregnaba aquel otro más antiguo, o, mejor, se estima al más moderno como la versión corregida, aumentada, puesta al día y constitucional de una formulación, carente de esa naturaleza en su origen pero no menos valiosa que la de una Constitución en orden a lograr la integración de cuantas comunidades religiosas convivan en un territorio sujeto a un mismo centro de poder.

Si no se encuentra el planteamiento descabellado, se hace abstracción del asunto relativo a la Jefatura del Estado, y se observan desde el punto de vista laico que consienten, no habrá diferencia entre la "Constitución de Medina" y la del Líbano que no pueda superarse salvando la distancia del tiempo que las separa, mediante la inmersión de la primera en la cultura de la que bebe la segunda, bastaría con eso para obte- 
ner su réplica y la de tantas otras Constituciones del Mediterráneo con ayuda de las cuales se ha construido el modelo de Constitución con que viene operándose en estas páginas.

A los Estados árabes les toca decidir y con toda seguridad que lo harán luego de evaluar no sólo cuáles son sus necesidades de todo tipo, incluidas, claro está, las de carácter integrador, sino de ponderar también si la obtención de este último beneficio subsiguiente a la adopción de un modelo constitucional enteramente laico no supondría poner en peligro su identidad cultural.

¡Aunque también a Israel podría interesarle adoptar una decisión de este tipo si, en verdad, media allí el propósito de poner término al statu quo que vertebra su sociedad política y aun su organización institucional, porque se juzgue que éste ha dado de sí cuanto podía; de modo que, en efecto, concluyan reconociéndose sus nacionales inmersos en un proceso de construcción estatal por culminar. Respecto del cual, interesa llamar la atención sobre el riesgo que arrostra cualquier Estado de comprometer seriamente su futuro si, al atravesar por la fase de su cimentación, ignora las peculiaridades privativas de las comunidades humanas ubicadas en su territorio, o pasa por alto, acerca de esas comunidades humanas diferentes entre sí que albergue, sus posibles pretensiones de imponerse sobre las restantes.

No se desdeñe el beneficio que puede reportarle a un Estado plural, en tanto que compositum de comunidades humanas culturalmente diversas, reconocerles su respectiva idiosincrasia y hasta asignarles, por eso mismo, alguna dosis de autonomía política, como medida disuasoria del secesionismo. Tampoco se menosprecie lo provechoso que puede ser para un Estado renunciar a toda clase de confesionalidad como medio de atajar los intentos protagonizables por cualquier comunidad religiosa nacional de implantar su libro sagrado como la norma suprema del Estado.

Dígase si una pretensión como ésa no encierra una tendencia desintegradora del Estado que pueda conducir a su fragmentación. De concluir en fracaso, por lo que éste significa de decepción para la comunidad religiosa comprometida con la iniciativa. De ser un éxito, por lo que supondría de desencanto para las restantes. $Y$, en cambio, adviértase cuanto representa para la integración de los diversos subsistemas estatales en el conjunto o sistema que el Estado cuente con una Constitución en la que reconozca la existencia autónoma de tales subsistemas y haga constar su compromiso de aconfesionalidad, pautada con arreglo al modelo que viene contemplándose, como garantía de neutralidad. 